\title{
O INGRESSO NA UNIVERSIDADE APÓS OS 45 ANOS: UM EVENTO NÃO-NORMATIVO
}

\author{
Denise Maria dos Santos Paulinelli Raposo* \\ Isolda de Araújo Günther"
}

\begin{abstract}
RESUMO. Examinam-se neste estudo as razões que levam à decisão de ingressar na universidade na idade adulta, um evento não dependente de gradação por idade, denominado pela perspectiva do curso de vida de evento não-normativo (nonnormative event). Os 40 participantes ( $27 \mathrm{~F}$ e $13 \mathrm{M}$ ), alunos de uma universidade particular do Centro-Oeste, com idades entre 45 e 60 anos, responderam a seis questões de uma entrevista estruturada, cujas respostas foram preenchidas pela primeira autora. Os resultados indicaram que os respondentes vivenciaram na vida adulta um período de estabilidade e que, embora conscientes das expectativas do seu ambiente quanto ao tempo e à seqüência das transições do ciclo de vida, avaliaram seus recursos pessoais, selecionaram seus objetivos e otimizaram suas capacidades de reserva antes de ingressar no ensino superior. Os resultados são discutidos à luz da perspectiva do curso de vida.
\end{abstract}

Palavras-chave: desenvolvimento adulto, evento não-normativo, perspectiva do curso de vida.

\section{ADMITTANCE TO THE UNIVERSITY AFTER AGE 45: A NON-NORMATIVE EVENT}

\begin{abstract}
The reasons for admittance to the university after age 45, a non-normative event according to the life-span perspective, are analyzed. Forty students ( 27 females and 13 males), between 45 and 60 years old, from a private university in the central-western region of Brazil responded to a structured interview administered and recorded by the first author. Results indicate that the respondents perceived their adult life as a period of stability. While conscious of the expectations of their environment as to the time and transitions in their life cycle, the respondents evaluated their personal resources, selected their objectives and optimized their capacities before entering university. These results are discussed according to the life-span perspective frame of reference.
\end{abstract}

Key words: Adult development, non-normative event, life-span perspective.

\section{EL INGRESO A LA UNIVERSIDAD DESPUÉS DE LOS 45 AÑOS: UN EVENTO NO-NORMATIVO}

RESUMEN. Se examinan en este estudio las razones que llevan a la decisión de ingresar a la universidad en la edad adulta, un acontecimiento no dependiente de gradación por edad, denominado por la perspectiva del curso de vida de evento nonormativo (non-normative event). Los 40 participantes $(27 \mathrm{M}$ y $13 \mathrm{H})$, alumnos de una universidad particular de la región centro-oeste brasileño, con edades entre 45 y 60 años, contestaron a seis preguntas de una encuesta estructurada cuyas respuestas fueron rellenadas por la primera autora. Los resultados indicaron que los respondientes vivenciaron en la vida adulta un periodo de estabilidad y que, aunque conscientes de las expectativas de su ambiente cuanto al tiempo y a la secuencia de las transiciones del ciclo de vida, evaluaron sus recursos personales, seleccionaron sus objetivos y optimizaron sus capacidades de reserva antes de ingresar en la enseñanza superior. Los resultados son discutidos a la luz de la perspectiva del curso de vida.

Palabras-clave: desarrollo adulto; evento no-normativo; perspectiva del curso de vida.

A Psicologia do Desenvolvimento contemporânea é o resultado de grandes transformações conceituais.
Disciplina inicialmente circunscrita ao estudo dos primeiros anos de vida, dedica-se atualmente a temas

* Pedagoga. Mestre em Psicologia pela Universidade Católica de Brasília. Consultora do Ministério da Educação.

\# Psicóloga, PhD em Psicologia do Desenvolvimento. Pesquisadora Associada Sênior, Instituto de Psicologia, Universidade de Brasília. 
que abrangem todo o ciclo vital. As contribuições de precursores desta orientação teórica, como do filósofo alemão Tetens, que publicou em 1777 o primeiro trabalho na perspectiva do ciclo de vida, e de Charlotte Bühler (1933/1959) que considerou o "desenvolvimento como um processo que se dá em toda a extensão da vida humana" (p. 46), foram difundidas no continente americano somente na década de 1970.

A publicação da coleção Life-Span Human Development (Troll, 1975; Kalish, 1982) propugnou uma maneira de estudar o desenvolvimento humano além da infância, baseada em metodologia e planejamento de pesquisa, em estudos longitudinais, em questionamentos sobre estabilidade e mudança. Autores como Baltes, Reese e Lipsitt (1980) reafirmaram que a preocupação desta orientação teórica é com “a descrição, explanação e modificação (otimização) dos processos do desenvolvimento no curso de vida humano do nascimento à morte" (p. 66). Note-se que os autores citados usaram indistintamente os conceitos "espaço de tempo de vida" (Life span) e 'curso de vida' (Life course). Em que sentido estas expressões são equivalentes? Em que sentido diferem?

Conforme Hagestad e Neugarten (1985), "Enquanto o primeiro - Life span - focaliza a atenção em fenômenos intrapsíquicos, o segundo -Life course enfatiza pontos de transição em que a 'pessoa social' passa por mudanças. A abordagem do curso de vida se concentra, em particular, em transições que são socialmente criadas, socialmente reconhecidas e socialmente compartilhadas" (p. 35). Adicione-se que o termo Life-course (curso de vida) também é usado no sentido de Life-cicle (ciclo de vida) e ambos sinalizam que as vidas humanas são influenciadas por múltiplas dimensões de tempo, i.é., pelos tempos biológico, social e histórico, relacionados respectivamente aos efeitos da maturação, de coorte ou geração e de período ou época.

Em 1970 Baltes e Goulet indicaram que a perspectiva do curso de vida inclui os seguintes componentes: a) estuda as mudanças que ocorrem no indivíduo à medida que os anos passam; b) verifica quais as observações sobre um grupo etário que se aplicam a outros grupos; c) verifica quais os dados que sugerem relação de causa e efeito. Posteriormente Baltes e Willis (1982) acrescentaram a dimensão da modificação ou otimização do comportamento ao longo do curso de vida; portanto, o desenvolvimento humano é concebido como uma mudança positiva (modificação/aperfeiçoamento/otimização) na capacidade de adaptação do indivíduo, na direção de um conjunto de metas desejáveis, que dependem da aplicação de comportamentos, de conhecimento cultural, de status físico, de comprometimento e de esforço para consecução das metas.

Pelo que nos consta, os primeiros manuais didáticos sobre desenvolvimento adulto em língua inglesa foram editados no fim dos anos 1970, sendo um destes Adult life, developmental process de Stevens-Long (1979). A partir desse marco, nos últimos vinte e cinco anos, a literatura especificamente relacionada ao envelhecimento da população não cessou de crescer. Não obstante, se considerarmos o número de pesquisas dedicadas ao desenvolvimento adulto, podemos afirmar que o estudo desta fase continua sendo negligenciado. $\mathrm{O}$ considerável interesse por conhecimentos que vão além da infância e da adolescência decorreu de mudanças demográficas, por sua vez atreladas a avanços no conhecimento científico que possibilitaram à população, maior longevidade e melhoria na qualidade de vida (Neri, 1995).

$\mathrm{Na}$ língua portuguesa a palavra adulto teve seu primeiro registro em 1551, no sumário da pregação fúnebre feita por Antônio Pinheiro, por ocasião da transladação dos ossos do Rei D. Manoel e da Rainha Dona Maria. O termo significa "que ou o que atingiu o máximo do seu crescimento e a plenitude das suas funções biológicas [homem, animal, planta]" (Houaiss \& Villar, 2001, p.93). Considerar o adulto nessa perspectiva estática - como um ser que já alcançou seu ápice - sugere que pouco desenvolvimento ou maturação ocorre após o alcance desse estágio. Como explicitado anteriormente, essa concepção, que de certa maneira impregnou a Psicologia do Desenvolvimento, foi abandonada (Troll, 1975) ao se constatar que, embora a fase adulta seja, comparativamente, um dos períodos mais estáveis do ciclo de vida, as pessoas mudam como consequiência de determinantes biológicos, de eventos de vida ou de expectativas sociais. Não se questiona, portanto, se a vida adulta é estruturada pelas convenções sociais, alicerçadas na biologia. O reconhecimento de que ocorrem variações culturais e subculturais pode advir da observação de que as tarefas da vida adulta, no que concerne aos integrantes da classe média, parecem obedecer a uma seqüência: espera-se que as pessoas se capacitem para assumir responsabilidades econômicas, casem-se, criem os filhos, permaneçam casados ou separem-se. Os que se dedicam a uma profissão prosseguem avançando na carreira até, finalmente, se aposentar. Ao descrever esses processos, Caspi, Elder e Bem (1987) referem-se a modos de desenvolvimento continuado e cumulativo que interagem entre si e ajudam o indivíduo a manter seus modos de 
funcionamento ao longo da vida. Por sua vez, Costa e McCrae (1989) alertam que este padrão observável assegura um quadro de referência básico para a Sociologia, entretanto, "Não há razão para descrevê-lo como desenvolvimento" (p. 49), uma vez que o desenvolvimento adulto ocorre quando as mudanças afetam a psicologia do indivíduo, i.é., "quando a pessoa se adapta e cresce com a experiência" (p. 50).

Uma antiga revisão da literatura realizada por Günther e Günther (1986) classificou estudos sobre os anos da vida adulta de acordo com as seguintes categorias: (a) idade cronológica (Levinson, Darrow, Klein, Levinson \& Mckee, 1977, 1978); (b) estágios do desenvolvimento (Erikson 1963; Gould 1978); (c) individualidade (Neugarten, 1968); (d) curso de vida (Baltes, 1979; Baltes, Reese \& Nesselroade, 1977; Labouvie-Vief, 1980); (e) transições do desenvolvimento (Lowenthal, Thurnher \& Chiriboga, 1975); (f) modelo centrado nas crises do desenvolvimento (Schlossberg, 1981).

Neri $(1991,1993,1995,2002)$ e Néri e Wagner (1985) usam como referencial teórico em seus estudos sobre envelhecimento e velhice a perspectiva do curso de vida, e afirmam que os processos de mudanças no ser humano ocorrem tanto ao longo da vida quanto em relação a um dado período, uma vez que o desenvolvimento é graduado por influências: a) normativas ligadas à gradação por idade; b) normativas ligadas à gradação pela história; c) nãonormativas.

Staudinger, Marsiske e Baltes (1995) explicitam que as influências graduadas por idade são normativas, uma vez que se apresentam por meio de determinantes biológicos e ambientais intimamente ligados à idade cronológica. As influências ligadas à gradação pela história, além de abrangerem os determinantes biológicos e ambientais, estão relacionadas ao tempo histórico. Por sua vez, a imprevisibilidade das influências não-normativas, associadas aos determinantes biológicos e ambientais, diferencia um indivíduo do outro, porquanto tais eventos não estão vinculados às influências normativas.

Estudos conduzidos por Baltes e Silverberg (1995) demonstram que em todas as fases da vida somos desafiados pelas próprias expectativas quanto ao futuro, por novas exigências ambientais, pelo desejo de progresso e pela contínua preocupação com o senso de controle, a integração e a produtividade social.

Assim sendo, para que o indivíduo mantenha seu bem-estar físico e social e acompanhe as mudanças e exigências da sociedade, faz-se necessário ter em conta o ambiente no qual vive, os valores sociais e individuais, bem como as circunstâncias de sua história de vida. Com base nestas proposições, Baltes (1997) elaborou o modelo de envelhecimento bemsucedido que defende o manejo dinâmico entre ganhos e perdas por meio da interação entre "Seleção, Otimização e Compensação" (SOC). Esse modelo agrega uma estrutura biológica e cultural que pode ser aplicada a qualquer teoria do desenvolvimento, uma vez que interage nas diferentes etapas da vida. Essa interação está relacionada aos movimentos que direcionam o indivíduo a atingir níveis mais altos de funcionamento (crescimento) e à possibilidade de criar barreiras diante de resultados negativos (manutenção).

$\mathrm{O}$ modelo SOC especifica que a seleção ocorre dentro de determinadas condições ou limitações de tempo e recursos. É um processo condicionado às disposições ou preferências comportamentais selecionadas pela evolução a partir da plasticidade associada à idade e aos objetivos do indivíduo. De acordo com Baltes (1997), envolve a seleção eletiva e a seleção baseada nas perdas. A seleção eletiva compreende a especificação de metas bem como sua hierarquia, contextualização e compromissos. A seleção baseada nas perdas avalia os objetivos mais importantes, a busca de novas metas, a adaptação a novos padrões.

A otimização está relacionada a uma concepção tradicional de desenvolvimento, entendido como um esforço para o aumento da eficácia por meio dos recursos pertinentes aos objetivos em busca de níveis mais altos de desempenho. Focaliza a atenção, o esforço, a energia na distribuição do tempo, na prática e na aquisição de novas habilidades, modelando outros recursos e tendo como motivação básica o desenvolvimento do ego.

A compensação tem origens múltiplas, possui formas variadas, sendo exemplificada quando um conjunto de recursos não está disponível, ou quando há uma perda direta desses meios por restrições de tempo e/ou de energia. Implica na necessidade do aumento da energia ou na distribuição do tempo por meio da ativação de novas habilidades ou do uso de recursos externos, como, por exemplo, óculos e bengala, com o objetivo de compensar as perdas.

Destarte o modelo SOC fundamenta-se nos princípios básicos dos benefícios da seleção evolutiva e da necessidade e eficiência da cultura. Investiga os estados incompletos do desenvolvimento humano e suas implicações, especificando que a maximização de ganhos e a minimização de perdas permitem uma possível equilibração do indivíduo que, por sua vez, é dependente do significado de ganhos e perdas, da 
idade, dos padrões de comportamento, dos contextos culturais e históricos, do bem-estar funcional, da adaptabilidade.

A psicologia do curso de vida entende que o indivíduo e o ambiente social atuam numa interação dinâmica, no sentido de que "o desenvolvimento é visto como um processo contínuo de adaptação que dura por toda a vida, relacionado a processos internos em interação com as atividades externas e os processos sócio-históricos" (Neri, 1995, p. 24).

A proposta desse estudo alicerça-se na perspectiva do curso de vida e investiga as razões que levam os indivíduos a assumir novos papéis, ao ingressar na universidade após os 45 anos. Para investigar esse evento não-normativo foram formuladas as seguintes questões:

1. O que leva as pessoas a partir dos 45 anos a ingressar na universidade?

2. Como essas pessoas integram este novo papel em suas vidas?

3. Quais suas expectativas em relação ao futuro?

\section{MÉTODO}

\section{Contexto da pesquisa}

A pesquisa foi realizada em uma instituição de ensino superior da Região Centro-Oeste que oferece cursos de graduação nas áreas de Administração, Ciências Contábeis, Pedagogia, Processamento de Dados e História e cursos de pós-graduação lato sensu nas áreas de Educação e Administração. A clientela consiste de alunos que viajam até $300 \mathrm{~km}$ por dia para freqüentar aulas no período noturno.

\section{Participantes}

Os 40 (27 mulheres e 13 homens) participantes deste estudo foram selecionados de acordo com os seguintes critérios: a) ter 45 (quarenta e cinco anos) ou mais; b) ser estudante de graduação da Instituição; c) estar cursando a graduação e não apenas matriculado(a) em disciplinas de dependência. Os entrevistados tinham em média 50 anos de idade. Vinte e quatro respondentes cursavam Pedagogia, oito Administração, quatro Ciências Contábeis, três, História e um, Processamento de Dados.

Mais da metade dos respondentes era constituída de casados, em média, há 25 anos, tendo entre um e quatro filhos por casa. Dois participantes pertenciam à etnia Xavante e tinham dez filhos cada. Dentre os entrevistados, 27 são procedentes da Região CentroOeste. As ocupações compreendiam: trabalho nas áreas da educação (27), trabalho como autônomo (12), dentre estes, alfaiate, pescador, agropecuarista, monitor bilíngüe indígena/professor de português. Com relação ao tempo de serviço dos entrevistados, quinze indicaram entre 20 e 29 anos. Os dados apontam que 24 dos sujeitos professam a religião católica.

\section{Instrumento}

Elaborou-se uma entrevista semi-estruturada contendo dez perguntas referentes aos dados demográficos e as oito questões que serão analisadas nesse artigo: a) Que curso freqüentou antes de ingressar na Instituição? b) Quanto tempo ficou sem estudar antes de ingressar na Instituição? c) Quando e por que voltou a estudar? d) Qual a expectativa que você tinha ao ingressar na Instituição? e) Como você se via antes e se vê após ingressar na Instituição? f) $\mathrm{O}$ que permanece igual e o que mudou em sua vida? g) Qual a coisa que você mais gosta na sua vida atual? h) $\mathrm{O}$ que você espera do futuro?

\section{Procedimento}

A pesquisadora obteve o consentimento dos entrevistados e manteve uma relação de acolhimento e confiança para assegurar informações diferenciadas e de qualidade. As entrevistas foram realizadas nos locais definidos e agendados pelos participantes, ou seja, no ambiente da Instituição, em suas residências ou em seus locais de trabalho.

\section{Análise dos Dados}

Os dados foram analisados por meio da análise de conteúdo. Optou-se pela utilização das seis etapas para a organização da análise do material simbólico descritas por Bardin (2005): (a) pré-análise; (b) codificação; (c) categorização; (d) tratamento dos dados; (e) inferência e (f) interpretação.

\section{RESULTADOS}

Objetivou-se neste estudo responder a três questões: o que leva as pessoas a partir dos 45 anos a ingressar na universidade? Como essas pessoas integram este novo papel em suas vidas? Quais são suas expectativas em relação ao futuro?

\section{O que leva uma pessoa a ingressar na universidade, após os 45 anos?}

Duas perguntas da entrevista informam sobre as razões que levaram as pessoas a ingressar na 
universidade após os 45 anos: a) Por que voltou a estudar? b) Qual a expectativa que você tinha ao ingressar na Instituição?

A resposta mais freqüente à pergunta "por que voltou a estudar?" foi realização pessoal (07 M e 14 F), seguida por, contato com as pessoas (04 M e $16 \mathrm{~F})$; objetivo de vida (10 M e $08 \mathrm{~F})$; adquirir conhecimento (07 M e $11 \mathrm{~F})$; mercado de trabalho (13 M e $04 \mathrm{~F})$; não parar no tempo (0 M e $04 \mathrm{~F})$; oportunidade $(01 \mathrm{M}$ e $03 \mathrm{~F}$ ); separação ( 0 M e $04 \mathrm{~F}$ ); melhorar o contato com a família ( $02 \mathrm{~F}$ ); aposentadoria (01 M e $01 \mathrm{~F})$.

Os relatos sobre a expectativa quando do ingresso na instituição revelaram conteúdos positivos e negativos. Dentre os conteúdos positivos chamam a atenção: necessidade de adquirir maior conhecimento (9 M e $6 \mathrm{~F}$ ); desejo de melhorar na profissão (6 M e 3 $\mathrm{F})$; segurança no potencial (04 M); compensar as perdas do casamento (04 F); buscar companheirismo (03 F); realizar um sonho $(03 \mathrm{M}$ e $04 \mathrm{~F})$; seguir um meta, desafio, dar exemplo aos filhos, dar exemplo à juventude e aposentadoria (com 01 resposta cada).

Os conteúdos negativos envolvem a expressão "não conseguir", sem maiores especificações (03 M e $06 \mathrm{~F})$; razões de ordem cognitiva - dificuldade de memória, de raciocínio, de aprendizagem - ( $04 \mathrm{M} \mathrm{e}$ $05 \mathrm{~F}$ ); razões de ordem emocional - vergonha, medo de humilhação, de enfrentar a diferença de idade, insegurança - (07 respostas F).

Os respondentes apontaram, ainda, obstáculos relacionados a problemas com a família, com os filhos e com o casamento. Referiram-se aos maridos que não permitiam o retorno de suas companheiras aos estudos; à doença na família; a pais analfabetos que afirmavam que "a mulher não trabalha, então não precisa estudar". Foram relatadas, também, dificuldades ligadas à falta de oportunidade na vida, ao fato que a escola "parecia não ser o meu lugar", ao desestímulo dos colegas. Obstáculos financeiros e profissionais, bem como falta de tempo, fizeram parte dos relatos.

Como essas pessoas integram este novo papel em suas vidas, foi a segunda questão pesquisada neste estudo. Três perguntas da entrevista buscam saber a maneira como os respondentes integram em suas vidas este novo papel, cursar uma universidade: a) Como você se via antes e se vê após ingressar na Instituição? b) $\mathrm{O}$ que permanece igual e o que mudou em sua vida? c) Qual a coisa de que você mais gosta na sua vida atual?

Os relatos referentes à primeira questão (como você se via antes, como você se vê após ingressar na Instituição?) indicaram que os respondentes se percebiam fracassados (25), desatualizados (17), com dificuldade de relacionamento (15). Após ingressar na Instituição, relataram melhoras no relacionamento com os colegas (27) e com os familiares (15), ampliação de conhecimento (9). Três respondentes do sexo feminino indicaram aumento de cobrança quanto às tarefas domésticas por parte dos maridos.

Quanto à questão "O que mudou e o que permaneceu igual em sua vida?", mais da metade dos respondentes indicou que tudo mudou. Os demais relataram que a vida social, o relacionamento em casa, o emprego, o modo de vida, a responsabilidade, a personalidade e a humildade não apresentaram mudança.

Quando lhes foi perguntado do que mais gostam na sua vida atual, apontaram. em primeiro lugar, a convivência com os familiares (23), incluindo a família nuclear e a família extensa. Outros aspectos apontados foram: estudar, viver, faculdade, companheirismo, lazer, casa, liberdade.

\section{Quais suas expectativas em relação ao futuro?}

As verbalizações quanto à terceira questão deste estudo, que corresponde à última pergunta da entrevista "Quais são as suas expectativas em relação ao futuro", indicaram o trabalho como o aspecto mais frequientemente mencionado. Um fator importante a ser ressaltado refere-se à expressão "um futuro melhor", mencionada por onze respondentes e exemplificada com menções a acontecimentos mundiais, nacionais e regionais, demonstrando interesse em melhorar a qualidade de vida da população de uma maneira geral. Sete respondentes mencionaram o desejo de ter uma velhice tranqüila para manter equilíbrio e estabilidade no fim da vida. Foram também indicadas as expectativas de terminar a faculdade, fazer pós-graduação, melhorar financeiramente, alcançar os objetivos e servir ao próximo.

\section{DISCUSSÃO}

Embora seja prudente não emitir opiniões generalizadas e contundentes sobre os dados de uma amostra composta por 40 respondentes, é possível, a partir dos resultados dessa pesquisa, apontar direções para estudos em maior escala.

Dos 40 participantes da pesquisa 27 são do sexo feminino e 13 do sexo masculino, 31 dos quais são casados entre 02 e 40 anos, com uma média de manutenção do casamento de 25 anos. Para as quatro pessoas separadas há menos de três anos, o ingresso na faculdade foi uma estratégia para obter 
experiências positivas que compensassem as perdas do casamento (Baltes, 1997). Embora não tenha sido objetivo desta pesquisa investigar questões de gênero, os resultados mostraram-se congruentes com as observações de Carter e McGoldrick (1995) quando salientam que a crise da meia-idade tem enviado às escolas e ao trabalho um número de mulheres sem precedente. As entrevistadas do gênero feminino mencionaram: "Convivi com uma pessoa que me podou muito, que tirou todas as oportunidades de sonho e eu tenho muitos sonhos a serem realizados", "Meu marido não me deixava ler. Agora, sozinha e sem marido, eu leio", "Fui podada a minha vida toda, por 29 anos", "Quando eu era casada, meu marido não me deixava estudar". Esses relatos sinalizam para rompimentos com antigos padrões e busca de novas metas (Baltes, 1997). Por outro lado, os entrevistados do gênero masculino não elencaram a separação como motivo para o ingresso na faculdade.

No que diz respeito à profissão, os resultados indicam que os respondentes, com tempo de serviço entre 10 e 40 anos, exercem práticas diversificadas, sendo a educação a atividade e fonte de renda comum a 15 das entrevistadas. Stein (1987) considera o campo da educação escolar uma das opções mais seguras de estabilidade profissional, principalmente em contextos rurais, onde a oportunidade de acesso ao emprego constitui uma dificuldade concreta. Os resultados apontam ainda que dois estudantes exercem a função de professor em sua tribo indígena e trabalham como monitores bilíngües, tendo 15 e 24 anos de exercício do cargo.

A variação de tempo em que os entrevistados ficaram sem estudar antes do ingresso na faculdade foi entre 10 e 19 anos, período no qual vivenciaram obstáculos familiares, sociais, pessoais, financeiros e profissionais, que lhes impediam o retorno aos estudos. Os meios encontrados para lidar com tais obstáculos serão discutidos a seguir.

\section{O que leva uma pessoa a ingressar no ensino superior com 45 anos?}

A teoria formulada por Baltes (1997) dá suporte à discussão dos dados, ao defender que a Seleção agrega um conjunto específico de metas escolhidas durante o ciclo de vida, que podem ser identificados neste estudo por meio dos seguintes conteúdos: "adquirir conhecimento", "objetivo de vida", "levar conhecimento para que a comunidade indígena ficasse esclarecida", "ajudar no encaminhamento dos filhos" (seleção eletiva). O sistema de hierarquia das metas pode ser constatado nas verbalizações: "São três realizações na vida: casar, ter filhos e estudar" e o compromisso com as metas com esses exemplos: "Sempre tive vontade de ter um curso superior"; "Eu sabia que era a hora de voltar"; "Incentivar os mais jovens da aldeia".

A Seleção baseada nas perdas revela ser a aposentadoria um dos motivos da busca de novas metas, pois pode ajudar no contato com as pessoas, no melhor relacionamento com os filhos, no desejo de refazer a vida, na adaptação a novos padrões exigidos pelo mercado de trabalho ou às exigências de novas legislações.

Com relação à otimização, os entrevistados mencionaram o desejo de adquirir novas habilidades e recursos, a necessidade de formação continuada, a possibilidade de modelar novas oportunidades que trouxessem como benefício o desenvolvimento do ego e a realização pessoal.

Verificou-se, no que diz respeito à compensação, um aumento do esforço e da energia, identificado nos relatos "para não parar no tempo"," para administrar o tempo disponível após a aposentadoria", bem como o "desejo de não se sentir excluído da sociedade".

Assim sendo, a busca de novos conhecimentos, associada a uma maior especialização na carreira e ao estabelecimento de novas prioridades na vida, pode amenizar as perdas inerentes aos limites da plasticidade individual por meio da ativação da capacidade de reserva (Baltes \& Baltes, 1990).

Os pontos negativos exemplificados nas expressões "não conseguir", "dificuldade de raciocínio", "dificuldade de memória" levam à compreensão de como as capacidades cognitivas podem minimizar as deteriorações do envelhecimento. Conforme mencionam Baltes (1997) e Schaie (1994), na idade adulta inicia-se um declínio dos mecanismos cognitivos relativos à memória, à rapidez em processar informações bem como à diminuição da capacidade de reserva. Entretanto, embora em estudos de laboratório os resultados indiquem que pessoas de 25 anos podem ter maior rapidez na execução das tarefas, no mundo real a aquisição de conhecimentos pode obscurecer as inevitáveis conseqüências do declínio relacionado à idade. O desempenho parece estar na dependência do tipo de tarefa que está sendo solicitado, sendo, em muitos trabalhos, uma conseqüência do "quanto você sabe e de quão bem você sabe e ambas [essas questões] aumentam dentro dos 60" (The ageing brain, 2006). Esses dados corroboram as observações de Baltes, Staudinger e Lindenberger (1999) quando afirmam que muitas vezes há uma manutenção dos mecanismos cognitivos até as fases mais avançadas da idade adulta, dependendo de fatores de experiência adquiridos durante o curso de vida. 
Cabe ressaltar ainda que a influência nãonormativa vivida pelos respondentes que possibilitou a ativação da resiliência e da capacidade de reserva proporcionou um crescimento considerado ótimo, além do nível normal de funcionamento, permitindo integrar novos papéis em suas vidas, conforme será apresentado a seguir.

Os resultados apontaram que após o ingresso no ensino superior os respondentes integraram novos papéis na área social, visto que a "melhora no relacionamento com os colegas" corresponde ao dado de maior freqüência demonstrado nesses relatos. Segundo Neri (1995), o processo de interação social contínuo produz uma agenda de desenvolvimento que envolve a prescrição de papéis e normas etárias, fazendo uso das potencialidades dos indivíduos. Essa afirmação pode ser verificada por meio dos dados que apontaram a maneira como os participantes se percebiam antes e se percebem após voltar a estudar, da indicação do que permaneceu igual e do que mudou em suas vidas, bem como daquilo de que eles mais gostam no presente.

Honzik (1984) observa que a maior questão levantada sobre o curso de vida se refere à natureza das mudanças que ocorrem durante o desenvolvimento e dos fatores que determinam tais mudanças. No caso dos respondentes desta pesquisa, as mudanças levaram à integração de novos papéis e contribuíram para compensar as perdas e selecionar novas metas de vida.

As mudanças mencionadas nos relatos apontam que com o ingresso na faculdade o aspecto mais relevante para os respondentes foi o "relacionamento com as pessoas". Esse achado é surpreendente do ponto de vista do desenvolvimento humano, uma vez que guarda semelhança com os resultados disponibilizados por Coleman (1975), baseados em pesquisa realizada nos anos 1950, os quais podem ser aplicados aos dias de hoje. Coleman constatou que, no contexto escolar de adolescentes, a escola era valorizada, sobretudo, pela oportunidade que oferecia para socialização com os amigos. No presente estudo, adultos que voltam a freqüentar instituições de ensino emitem opinião semelhante. Cabe ainda ressaltar os registros sobre a importância, para os respondentes, de serem aceitos na turma em que estão matriculados, sobre a facilidade com que se inseriram em grupos de estudos, a satisfação por conviver com pessoas mais jovens e a integração deste novo papel em suas vidas. Portanto, ir à faculdade e conviver com outras pessoas eram fatores relacionados à manutenção e ao desenvolvimento das habilidades.

$\mathrm{O}$ registro da maneira como os respondentes se percebiam antes e após ingressar na faculdade, as mudanças e estabilidades vivenciadas, a avaliação das experiências passadas comparadas às experiências presentes, exemplificam o que os teóricos denominam de mudanças que impulsionam o desenvolvimento de forma multidirecional e multidimensional. A vivência desses novos papéis induziu, por sua vez, a visualização das expectativas futuras.

Baltes e Baltes (1990) mencionam o interesse na investigação dos mecanismos compensatórios e adaptativos realizados por estudiosos do envelhecimento nos últimos anos, objetivando identificar pontos de vista diferenciados sobre o que possibilita envelhecer bem. Nessa perspectiva, clarificar as expectativas dos respondentes tendo por base dados de pessoas com idades entre 45 e 60 anos contribui para o entendimento das metas de vida e de como tais metas estão sendo otimizadas no presente, como se relacionam às perspectivas futuras.

Identificam-se, nos dados relacionados às expectativas futuras, referências à situação econômica, à realização pessoal e ao desejo de melhoraria profissional, mencionadas por dez respondentes homens e por cinco mulheres. Contudo, os dados apontam para outro fator, inserido na melhora profissional e ligado à realização pessoal. Segundo Robbins (1999), a necessidade do indivíduo de desempenhar uma função que possibilite a utilização de suas habilidades é uma maneira de contribuir para sua realização pessoal. Por outro lado, associando esse achado à expressão futuro melhor, verifica-se que essa referência não se restringe à vida pessoal de cada respondente, mas diz respeito ao desejo de uma humanidade mais solidária, exemplificado na expressão servir ao próximo, e de uma sociedade mais igualitária, identificado na expressão mundo melhor e ilustrado por menções a acontecimentos mundiais, nacionais e regionais.

Nesta perspectiva, a velhice tranqüila, projetada como compensação de todo o investimento pessoal, social e econômico feito durante a vida, é apontada nos relatos dos respondentes. Tais relatos demonstram a seleção de metas e compensação das perdas ocorridas no decorrer de suas vidas, tendência que parece estar de acordo com a afirmação de Néri (1993) segundo a qual "envelhecer bem significa estar satisfeito com a vida atual e ter expectativas positivas em relação ao futuro" (p.11).

Baltes e Baltes (1990) sugerem que o desenvolvimento humano bem-sucedido ao longo da vida caracteriza-se pelo uso da estratégia de seleção, otimização e compensação. Entendemos nesses relatos que, a partir do momento em que os respondentes ingressaram no ensino superior, buscaram níveis mais altos de funcionamento 
(seleção). Desse modo, otimizaram sua capacidade de reserva com o intuito de compensar as perdas ocorridas durante o curso de suas vidas.

Quando esses respondentes projetam uma velhice tranqüila estão prevendo que no futuro as perdas serão maiores que os ganhos, e assim já começam a selecionar e otimizar suas metas para compensar essas perdas. Neri (1995) exemplifica este aspecto, mencionando a perda generalizada na capacidade de reserva. Com tal sequiela, advinda do processo biológico natural do envelhecimento, torna-se mais difícil a manutenção de níveis mais altos de funcionamento nos domínios ativos. Assim, na amostra estudada, a seleção de atividades cognitivas, no presente, pode ser um fator que virá a contribuir para uma velhice bem-sucedida.

Por outro lado, constata-se a importância de essas pessoas romperem com o habitual, o mais fácil, o mais aceito, buscando compensar as perdas vivenciadas no curso de vida e/ou viabilizar recursos disponíveis. Desse modo, ingressaram numa etapa marcada por um evento não-normativo e tiveram que otimizar suas habilidades, sua plasticidade e capacidade de reserva, após selecionarem suas metas.

\section{CONSIDERAÇÕES FINAIS}

O estudo em questão serviu como um ponto de apoio para a articulação entre a teoria e a prática, uma vez que possibilitou a compreensão das razões pelas quais pessoas na faixa etária entre 45 e 60 anos ingressam num curso superior. $O$ processo de integralização e interação social, legitimado pelo meio social e pela convivência com pares de outra faixa etária, parece validar a adoção de novos papéis e possibilitar o cultivo de expectativas que se projetam para o futuro.

Embora as observações a seguir se refiram a apenas dois entrevistados, chamamos a atenção para os dois Xavantes, que representam um elo cultural com descendentes dos primeiros habitantes do nosso país. Estes dois integrantes de uma tribo indígena atuam como mediadores culturais (Coelho \& Ahmed, 1980) e expressam a perspectiva futura de "voltar para a aldeia para ensinar o que aprendi", possibilitando aos demais colegas um ponto de convergência com os valores indígenas.

Considerando-se os resultados apresentados, o impacto de eventos não-normativos nos participantes deste estudo projeta-se positivamente, pois não limita suas vidas à espera resignada da passagem dos dias. As mudanças demográficas presenciadas no século XXI trouxeram visibilidade para a terceira idade. Faz-se imperativo repensar teorias, ampliar conceitos, não se limitar às idéias sobre apogeu, declínio biológico, degeneração (Honzik, 1984), como apanágio da vida adulta.

A partir dos resultados deste estudo dois grupos distintos foram delineados. Os relatos das mudanças verbalizadas pelos participantes do gênero masculino apresentaram-se, quando comparados com os do gênero feminino, com menor grau de intensidade emocional. Para os homens os novos papéis foram descritos como menos desafiadores, talvez como decorrência de uma cultura na qual eles, os homens, sempre foram reforçados em sua competência, confirmada pelos pais, pela escola e pela sociedade. Já para as mulheres as mudanças foram sentidas como um renascimento na esfera da família, do trabalho, do meio social.

Pesquisas futuras poderão aprofundar questões referentes à otimização de recursos no processo de aprendizagem em pessoas da terceira idade; às diferenças de gênero relacionadas ao ingresso na universidade na terceira idade; ao ajustamento familiar do indivíduo após $\mathrm{o}$ ingresso na universidade na idade adulta.

$\mathrm{O}$ avanço da ciência possibilita novos questionamentos, embasados em teorias que permitem o diálogo sobre temas fascinantes e fornecem aos pesquisadores oportunidades para investigar essa importante área da Psicologia do Desenvolvimento: o desenvolvimento adulto.

$\mathrm{Na}$ perspectiva das autoras, o sentimento mais marcante que permeou a realização dessa pesquisa pode ser resumido em uma frase: é importante adicionar mais vida aos anos, e não, simplesmente, mais anos à vida.

\section{REFERÊNCIAS}

Baltes, M. M. \& Silverberg, S. (1995). A dinâmica dependência autonomia no curso de vida. Em A. L. Neri (Org.), Psicologia do envelhecimento (pp.73-110). Campinas,SP: Papirus.

Baltes, P. B. (1979). Life-span developmental psychology: Some converging observations on history. In P. B. Baltes \& O. G. Brim, Jr. (Eds.), Life-span development and behavior, 2 (pp. 255-279). New York, NY: Academic.

Baltes, P. B. (1997). On the incomplete architecture of human ontogeny: Selection, optimization, and compensation as foundation of developmental theory. American Psychologist, $52,366-380$.

Baltes, P. B. \& Baltes, M. M. (1990). Psychological perspectives on successful aging: The model of selective optimization with compensation. In P. B. Baltes \& M. M. Baltes (Eds.), Successful aging. Perspectives from behavioral sciences (pp. 134). New York, NY: Cambridge University

Baltes, P. B. \& Goulet, L. R. (1970). Status and issues on life-span developmental psychology. In L. R. Goulet \& P. B. Baltes (Eds.), Life-span developmental psychology: Research and theory (pp. 4-21). New York, NY: Academic. 
Baltes, P. B., Reese, H. W. \& Lipsitt, L. (1980). Life-span developmental psychology. Annual Review of Psychology, 31, 65-110.

Baltes, P. B., Reese, H. W. \& Nesselroade, R. J. (1977). Life-span developmental psychology: Introduction to research methods. Monterey, CA: Brooks/Cole.

Baltes, P. B., Staudinger, U. M. \& Lindenberger, U. (1999). Lifespan psychology: Theory and application to intellectual functioning. Annual Review of Psychology, 50, 471-507.

Baltes, P. B. \& Willis, S. L. (1982). Plasticity and enhancement of intellectual functioning in old age. In F. I. M. Craik \& E. E. Trehub (Eds.), Aging and cognitive processes (pp. 353-389). New York, NY: Plenum.

Bardin, L. (2005, 11e. éd.). L'analyse de contenu. Paris: Universitaires de France.

Bühler, C. (1959, 2a . ed.). Der menschliche Lebenslauf als psychologisches Problem. Göttinger, DE: Verlag für Psychologie. (Original publicado em 1933).

Carter, B. \& McGoldrick, M. (1995). As mudanças no ciclo de vida familiar. Porto Alegre: Artes Médicas.

Caspi, A., Elder, G. H. Jr. \& Bem, D. J. (1987). Moving against the world: Life-course patterns of explosive children. Developmental Psychology, 23, 308-313.

Coelho, G. V. \& Ahmed, P. I. (1980). Uprooting and development. New York: Plenum.

Coleman, J. S. (1975). The transition from youth to adult. In R. E. Muuss (Ed.), Adolescent behavior and society a book of readings (pp. 627-633). New York: Random House.

Costa, P. T. Jr. \& Mcrae, R. R. (1989). Personality continuity and the changes of adult life. In M. Storandt \& G. R. VandenBos (Eds.), The adult years: Continuity and Change (pp. 45-77). Washington, DC: APA.

Erikson, E. (1963). Childhood and society. New York: Norton

Gould, R. L. (1978). Transformations: Growth and change in adult life. New York: Simon \& Schuster.

Günther, I. A. \& Günther, H. (1986). Desenvolvimento adulto entre estudantes brasileiros nos EUA: em busca de um modelo. Estudos de Psicologia (Campinas), 3, 84-105.

Hagestad, G. \& Neugarten, B. (1985). Age and the life-course. In R. Binstock \& Shanas (Eds.), Handbook of aging and society $\left(2^{\text {nd }}\right.$. ed., pp. 35-61). New York, NY: Van Nostrand-Reinhold.

Honzik, M. P. (1984). Life-span development. Annual Review of Psychology, 35, 309-31.

Houaiss, A. \& Villar, M. S. (2001). Dicionário Houaiss da Língua Portuguesa. Rio de Janeiro: Objetiva.

Kalish, R. B. (1982, $2^{\text {nd }}$. ed.). Late adulthood: Perspectives on human development. Monterey, CA: Brooks/Cole.

Labouvie-Vief, G. (1980). Beyond formal operations: Use and limits of pure logic in life-span development. Human Development, 23, 141-161.
Levinson, D. J., Darrow, C. N., Klein, E. B., Levinson, M. G. \& Mckee, B. (1976). Periods in the adult development of men: Ages 18 to 45. The Counseling Psychologist, 6, 21-25.

Levinson, D. J., Darrow, C. N., Klein, E. B., Levinson, M. G. \& Mckee, B. (1978). The seasons of a man's life. New York: Knopf.

Lowenthal, M. F., Thurnher, M. \& Chiriboga (Eds.) (1975). Four stages of life. San Francisco, CA: Jossey-Bass.

Neri. A. L. (1991). Envelhecer num país de jovens: significados de velho e velhice segundo brasileiros não idosos. Campinas, SP: EdUnicamp.

Neri, A. L. (1993). Qualidade de vida no adulto maduro: interpretações teóricas e evidências de pesquisa. Em A. L. Neri (Org.), Qualidade de vida e idade madura (pp. 9-55). Campinas, SP: Papirus.

Neri, A. L. (1995). Psicologia do envelhecimento: uma área emergente. Em A. L. Neri (Org.). Psicologia do envelhecimento (pp. 13-40). Campinas, SP: Papirus.

Neri, A. L. (2002). Bienestar subjetivo en la vida adulta y en la vejez: Hacia una Psicologia Positiva en América Latina. Revista Latinoamericana de Psicologia, 34, 55-74.

Neri. A. L. \& Wagner, E. C. de A. M. M. (1985). Opinião de pessoas de diferentes faixas etárias sobre a velhice: um estudo exploratório. Estudos de Psicologia, 02, 81-104.

Neugarten, B. L. (1968). Adult personality: Toward a psychology of the life cycle. In B. L. Neugarten (Ed.), Middle age and aging. Chicago: University.

Robbins, S. (1999). Comportamento organizacional. Rio de Janeiro, GB: LTC.

Schaie, K. W. (1994). The course of adult intellectual development. American Psychologist, 49, 304-313.

Schlossberg, N. K. (1981). A model for analyzing human adaptation to transition. The Counseling Psychologist, 51, 702-714.

Staundinger, U. M., Marsiske, M. \& Baltes, P. B. (1995). Resiliência e níveis de capacidade de reserva na velhice: perspectivas da teoria de curso de vida. Em A. L. Neri (Org.), Psicologia do envelhecimento (pp. 195-228). Campinas, SP: Papirus.

Stein, S. A. (1987). Por uma educação libertadora. Petrópolis: Vozes.

Stevens-Long, J. (1979). Adult life: Developmental processes (549 p.). Los Angeles, CA: Mayfield.

The ageing brain. Wisdom or senility. (2006, February, 18 -24). The Economist, 378(8465), 66.

Troll, L. E. (1975). Early and Middle Adulthood: The best is yet to be. (Life-span human development series). Monterey, CA: Brooks/Cole.

Recebido em 27/04/06 Aceito em 20/09/06

Endereço para correspondência: Denise Maria dos Santos Paulinelli Raposo. SQN 215, Bloco K, ap. 408, CEP 70.874-110, Brasília-DF. E-mail: denisepaolo@gmail.com 